\title{
Bedside differentiation of vestibular neuritis from central "vestibular pseudoneuritis"
}

\author{
C D Cnyrim, ${ }^{1}$ D Newman-Toker, ${ }^{2}$ C Karch, ${ }^{1}$ T Brandt,, Michael Strupp ${ }^{1}$
}

${ }^{1}$ Department of Neurology, University of Munich, Munich, Germany; ${ }^{2}$ Departments of Neurology and Otolaryngology, Johns Hopkins University School of Medicine, Baltimore, USA

Correspondence to:

Dr C D Cnyrim, Department of Neurology, University of Munich, Marchioninistr 15, D-81377

Munich, Germany:

christian.cnyrim@

charite.de

Received 2 May 2007

Revised 17 October 2007

Accepted 22 October 2007

\begin{abstract}
Acute unilateral peripheral and central vestibular lesions can cause similar signs and symptoms, but they require different diagnostics and management. We therefore correlated clinical signs to differentiate vestibular neuritis (40 patients) from central "vestibular pseudoneuritis" (43 patients) in the acute situation with the final diagnosis assessed by neuroimaging. Skew deviation was the only specific but non-sensitive (40\%) sign for pseudoneuritis. None of the other isolated signs (head thrust test, saccadic pursuit, gaze evoked nystagmus, subjective visual vertical) were reliable; however, multivariate logistic regression increased their sensitivity and specificity to $92 \%$.
\end{abstract}

The 1-year prevalence of vestibular vertigo in the general population is $5 \%,{ }^{1}$ and it accounts for approximately $1 \%$ of all emergency department visits. ${ }^{2}$ A subset of these patients suffers the rapid onset of sustained vertigo, nausea and vomiting (in association with nystagmus, unsteady gait and head motion intolerance) known as the acute vestibular syndrome. This clinical syndrome lasts for days to weeks and is most often caused by vestibular neuritis $(\mathrm{VN}),{ }^{3}$ rarely by labyrinthitis which is characterised by associated auditory symptoms. ${ }^{4}$ Most cases of the acute vestibular syndrome are "peripheral" (ie, reflect disease in the eighth nerve and/or labyrinth) and presumed viral in aetiology. ${ }^{3}$ However, it is well recognised that a subset of such vertiginous patients have, instead, an acute "central" vestibular syndrome, so-called "vestibular pseudoneuritis" (VPN). It is caused by unilateral (fascicular) lesions of the entry zone of the eighth nerve, ${ }^{4}$ vestibular nucleus lesions or vestibulocerebellar lesions, ${ }^{56}$ mostly caused by infarctions or multiple sclerosis plaques. Signs and symptoms may mimic VN, if there are no additional clinical brainstem and/or cerebellar signs. Differentiation of VN from VPN is clinically very relevant because patients with vascular VPN (who might otherwise recover well) may suffer a second, preventable infarction of the brainstem and/or cerebellum.? Therefore, in cases of central vestibular syndrome, further diagnostics (eg, MRI, Doppler sonography) and management (eg, thrombolysis) is warranted. In contrast, VN simply requires caloric testing and early onset treatment with glucocorticosteroids. ${ }^{8}$

The aim of this study was to identify simple bedside signs that reliably differentiate VN from VPN in the emergency unit.

\section{PATIENTS AND METHODS}

We retrospectively analysed clinical signs and bedside tests in 83 patients who presented at our department with rotatory vertigo, horizontalrotational nystagmus and postural imbalance, without additional non-vestibular inner ear, brainstem or cerebellar symptoms in the period 19952005. All patients underwent standardised history taking and complete standardised neurological, neuro-ophthalmological and neuro-otological examination ${ }^{9}$ by a specialist for neurology and a neuro-orthoptist within the first $48 \mathrm{~h}$ after onset of symptoms. They underwent electronystagmography with caloric irrigation and cranial MRI with high resolution imaging of the brainstem and cerebellum, including diffusion weighted MRI, not later than $72 \mathrm{~h}$ after presentation at our clinics. In a subgroup of 28 consecutive patients included after 2002, video-oculography (VOG) was recorded in darkness and during visual fixation.

The following clinical parameters, which can easily be assessed in the emergency room, were evaluated: (a) gaze evoked nystagmus towards the affected ear ("gaze evoked" nystagmus towards the unaffected ear can simply be caused by spontaneous nystagmus); (b) smooth pursuit, especially vertically; (c) head thrust test, as described by Halmagyi and Curthoys ${ }^{10}$; (d) skew deviation; and (e) subjective visual vertical (SVV). ${ }^{9}$ Another parameter tested for its diagnostic value was suppression of spontaneous nystagmus by visual fixation. This was assessed by measuring horizontal peak slow phase velocity, both in darkness and during fixation of a stationary LED by VOG, as described previously. ${ }^{11}$

\section{Inclusion criteria}

Assessment of the diagnosis of VN was based on four criteria: (1) history of acute or subacute onset of prolonged rotatory vertigo and postural imbalance; (2) horizontal spontaneous nystagmus with a rotational component; (3) hypo-/ non-responsiveness to caloric irrigation of the horizontal canal of the affected ear; and (4) no brainstem or cerebellar lesions on high resolution cranial MRI. Assessment of the diagnosis of VPN was based on the above criteria (1) and (2) in addition to (3) hyporesponsiveness to caloric irrigation (not mandatory) and (4) pathological findings in cranial MRI such as acute lesions of the brainstem (including the fascicular portion of the eighth nerve and/or the vestibular nuclei) and/or cerebellum (nodulus, medial branch of posterior inferior cerebellar artery territory). Exclusion criteria were a history of vestibular dysfunction before the acute onset of symptoms, additional cochlear symptoms (tinnitus or acute hearing loss), other signs or symptoms of brainstem or cerebellar disorders. 
Figure 1 Feed-forward neural net classifier for differentiation between vestibular neuritis and central "vestibular pseudoneuritis" based on three categorical (gaze evoked nystagmus, saccadic pursuit, head thrust test) and two continuous parameters (skew deviation, subjective visual vertical (SVV)). Each input neuron is activated according to a ramp-shaped (top three) or sigmoid (bottom two) function with the respective input parameter as the independent variable. The output activation function of the neuron is also sigmoid and depends on the activation status of the input neurons and the respective weight of each input (w1-5). Activation of the output neuron indicates pseudoneuritis, deactivation suggests vestibular neuritis. Activation functions and weights are fitted with a

backpropagation algorithm based on a "lesson" of datasets with given input and output parameters.

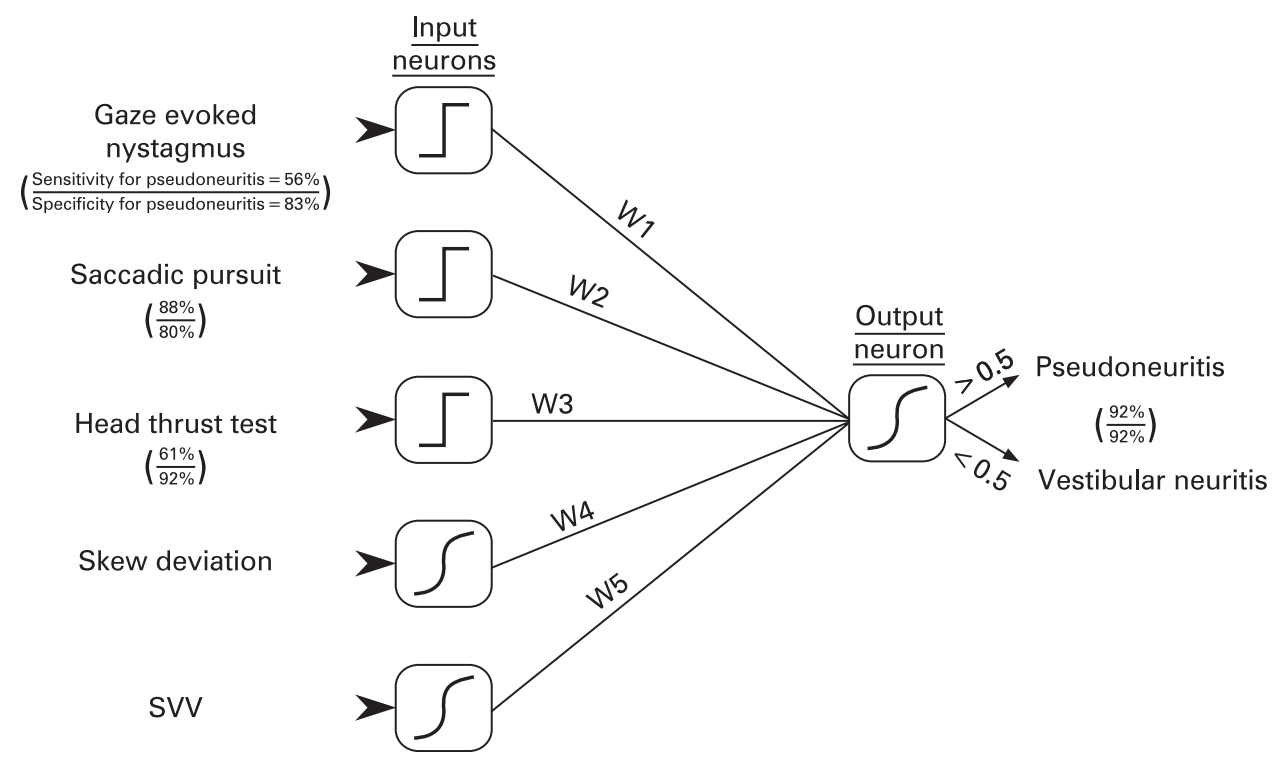

\section{Statistical analysis}

Correlation between single clinical parameters and the definite diagnosis was calculated by a $\chi^{2}$ test for categorical parameters and a logistic regression for continuous measures. To differentiate between VN and VPN utilising several clinical parameters, a multivariate approach in terms of a logistic regression was applied (fig 1). Mean peak slow phase velocities of the horizontal component of the spontaneous nystagmus, measured by VOG, were determined in complete darkness and during fixation of a stationary LED separately. A repeated measures ANOVA was used to evaluate group differences. Statistics were calculated with SPSS (V.12.0.1) and MemBrain (V.02.01.04.02) software on a PC. A p value of $<0.05$ was considered significant.

\section{RESULTS}

Forty patients fulfilled the four criteria mentioned above for VN and 43 for VPN (table 1). VPN was caused by acute infarctions $(n=23)$, multiple sclerosis plaques $(n=12)$ or another aetiology ( $\mathrm{n}=8$; eg, haemorrhage).

Skew deviation was detected in 17 patients with VPN (median $3^{\circ}$ ), but in none with VN $(\mathrm{p}<0.01)$. Thus this sign was specific but of low sensitivity (40\%). A vertical saccadic pursuit was found in $88 \%$ of cases of VPN but in only $20 \%$ of $\mathrm{VN}$ cases $(p<0.01)$. A pathological head thrust sign was found more often in VN (92\%) than in VPN (39\%; p <0.01). Fifty-six per cent of patients with VPN had a gaze evoked nystagmus contralateral to the direction of spontaneous nystagmus, but only $17 \%$ of patients with VN $(p<0.01)$. The SVV deviated in all patients of both groups from true vertical towards the affected side (median in VPN 7.9 ${ }^{\circ}$, in VN 7.3 ; p $=0.87$ ). Table 1 shows the frequencies of all categorical signs. Skew deviation, smooth pursuit deficit and head thrust test correlated best with the diagnoses assessed by MRI (table 1), but none of the analysed single signs was sufficiently sensitive and specific. The multivariate logistic regression approach (fig 1) improved reliability of the clinical signs for accurate classification to $92 \%$. Sensitivity and specificity for detection of VPN were both $92 \%$.

Mean peak slow phase velocity of spontaneous nystagmus, determined by VOG recordings, decreased during fixation of a target compared with complete darkness at $5.92 \%$ s on average in 11 patients with VN $(p<0.01)$. In $17 \mathrm{VPN}$ patients, the horizontal slow phase velocity decreased less (at $0.78 \%$ on average; $p=0.51)$. Repeated measures ANOVA revealed a group difference $(p<0.01)$.

\section{DISCUSSION}

The clinical differentiation of VPN from VN in the emergency room is reliably possible when additional non-vestibular signs and/or symptoms are present. If the patient presents without

Table 1 Clinical characteristics, frequencies of categorical clinical signs, group differences and correlation between signs/parameters and final diagnosis.

\begin{tabular}{lllll}
\hline & $\begin{array}{l}\text { Vestibular } \\
\text { pseudoneuritis }\end{array}$ & $\begin{array}{l}\text { Vestibular } \\
\text { neuritis }\end{array}$ & $\begin{array}{l}\text { Group } \\
\text { difference } \\
\text { (test) }\end{array}$ & $\begin{array}{l}\mathbf{R}^{2} \text { (correlation } \\
\text { assessed by) }\end{array}$ \\
\hline $\mathrm{n}$ & 43 & 40 & & \\
Age (y) (mean (SD)) & $53(17)$ & $54(14)$ & $\mathrm{p}=0.82$ (t test) \\
Sex (F:M) & $24: 19$ & $20: 20$ & $\mathrm{p}=0.60$ ( $\chi^{2}$ test) \\
Side of lesion (left:right) & $23: 20$ & $24: 16$ & $\mathrm{p}=0.55\left(\chi^{2}\right.$ test) & \\
Frequency of smooth pursuit deficit (\%) & 88 & 20 & $\mathrm{p}<0.01\left(\chi^{2}\right.$ test) & 0.37 ( $\chi^{2}$ test) \\
Frequency of gaze evoked nystagmus (\%) & 56 & 17 & $\mathrm{p}<0.01\left(\chi^{2}\right.$ test) & 0.12 ( $\chi^{2}$ test) \\
Frequency of skew deviation (\%) & 40 & 0 & $\mathrm{p}<0.01\left(\chi^{2}\right.$ test) & 1.00 (logistic regression) \\
Frequency of pathological head thrust sign (\%) & 39 & 92 & $\mathrm{p}<0.01\left(\chi^{2}\right.$ test) & 0.26 ( $\chi^{2}$ test) \\
Frequency of subjective visual vertical (\%) & 100 & 100 & $\mathrm{p}=1\left(\chi^{2}\right.$ test) & 0.01 (logistic regression) \\
\hline
\end{tabular}


non-vestibular signs, differentiation remains challenging. Currently, it is our clinical practice to run an MRI when patients fulfil the above mentioned criteria (1) history of acute or subacute onset of prolonged rotatory vertigo and postural imbalance and (2) horizontal spontaneous nystagmus with a rotational component, and one or more of the following conditions: (a) skew deviation, (b) gaze evoked nystagmus towards the affected ear (opposite in direction of spontaneous nystagmus), (c) vertical saccadic pursuit, (d) normal head thrust test or (e) severe or multiple vascular risk factors.

How can the results of this study improve our clinical practice? The only specific diagnostic sign in this study was central vertical divergence of the visual axes (skew deviation). Previous studies, however, have reported on the occurrence of skew deviation caused by rare peripheral conditions with a complete unilateral peripheral vestibular deficit (ie, of the pars superior and inferior of the vestibular nerve (eg, Ramsay-Hunt syndrome $\left.\left.{ }^{12}\right)\right) .{ }^{13-15}$ The clinical relevance is further limited by its low sensitivity (40\%). All other single clinical signs in this study provide insufficient specificity and sensitivity. When all five signs are combined (gaze evoked nystagmus, saccadic pursuit, head thrust test, skew deviation, SVV), however, sensitivity and specificity increased to $92 \%$, as demonstrated by multivariate logistic regression (fig 1). To apply and further improve this simple diagnostic tool, a central database is required, which must be fed with clinical parameters and the final diagnosis assessed by MRI of a large sample of patients. We therefore plan to establish an internet based database on our webpage (www. schwindelambulanz-muenchen.de). The computational learning process will further increase sensitivity and specificity of the classifier, and in a second stage the tool could instantaneously indicate the probable diagnosis (without obligation) for registered users entering their patient data.

In addition, analysis of the subgroup in which visual fixation suppression of spontaneous nystagmus was determined by
VOG revealed the high diagnostic value of this sign. For clinical application, however, automated VOG systems are necessary, and sensitivity and specificity of the differentiation based on reduction of horizontal slow phase velocity (with a cut-off value) must be elaborated in a larger sample of patients.

Acknowledgements: We thank Ms Judy Benson for copy editing the manuscript. Competing interests: None.

Ethics approval: Ethics approval was obtained.

\section{REFERENCES}

1. Neuhauser HK, von Brevern M, Radtke A, et al. Epidemiology of vestibular vertigo: a neurotologic survey of the general population. Neurology 2005;65:898-904.

2. Cappello M, di Blasi U, di Piazza L, et al. Dizziness and vertigo in a department of emergency medicine. Eur J Emerg Med 1995;2:201-11.

3. Theil D, Arbusow V, Derfuss T, et al. Prevalence of HSV-1 LAT in human trigeminal, geniculate, and vestibular ganglia and its implication for cranial nerve syndromes. Brain Pathol 2001;11:408-13.

4. Thomke F, Hopf HC. Pontine lesions mimicking acute peripheral vestibulopathy. J Neurol Neurosurg Psychiatry 1999;66:340-9.

5. Mossman S, Halmagyi GM. Partial ocular tilt reaction due to unilateral cerebellar lesion. Neurology 1997;49:491-3.

6. Lee H, Sohn SI, Cho YW, et al. Cerebellar infarction presenting isolated vertigo: frequency and vascular topographical patterns. Neurology 2006;67:1178-83.

7. Heros RC. Cerebellar hemorrhage and infarction. Stroke 1982;13:106-9.

8. Strupp M, Zingler VC, Arbusow V, et al. Methylprednisolone, valacyclovir, or the combination for vestibular neuritis. N Engl J Med 2004;351:354-61.

9. Brandt T, Strupp M. General vestibular testing. Clin Neurophysio/ 2005;116:406-26.

10. Halmagyi GM, Curthoys IS. A clinical sign of canal paresis. Arch Neurol 1988;45:737-9.

11. Pereira CB, Strupp M, Eggert T, et al. Nicotine-induced nystagmus: threedimensional analysis and dependence on head position. Neurology 2000;55:1563-6.

12. Schulz P, Arbusow V, Strupp M, et al. Sympathetic contralateral vestibulopathy after unilateral zoster oticus. J Neurol Neurosurg Psychiatry 1999;66:672-6.

13. Vibert D, Hausler R, Safran AB, et al. Diplopia from skew deviation in unilateral peripheral vestibular lesions. Acta Otolaryngol 1996;116:170-6.

14. Vibert D, Hausler R, Safran AB, et al. Ocular tilt reaction associated with a sudden idiopathic unilateral peripheral cochleovestibular loss. ORL J Otorhinolaryngol Relat Spec 1995;57:310-15.

15. Wolfe GI, Taylor CL, Flamm ES, et al. Ocular tilt reaction resulting from vestibuloacoustic nerve surgery. Neurosurgery 1993;32:417-20. 
JNNP

\section{Bedside differentiation of vestibular neuritis from central "vestibular pseudoneuritis"}

C D Cnyrim, D Newman-Toker, C Karch, et al.

J Neurol Neurosurg Psychiatry 2008 79: 458-460

doi: 10.1136/jnnp.2007.123596

Updated information and services can be found at:

http://jnnp.bmj.com/content/79/4/458.full.html

\begin{tabular}{cl}
\hline References & $\begin{array}{l}\text { These include: } \\
\text { This article cites } 15 \text { articles, } 7 \text { of which can be accessed free at: } \\
\text { http://jnn.bmj.com/content/79/4/458.full.html\#ref-list-1 } \\
\text { Article cited in: } \\
\text { http://jnn.bmj.com/content/79/4/458.full.html\#related-urls }\end{array}$ \\
$\begin{array}{c}\text { Email alerting } \\
\text { service }\end{array}$ & $\begin{array}{l}\text { Receive free email alerts when new articles cite this article. Sign up in } \\
\text { the box at the top right corner of the online article. }\end{array}$ \\
Tollections & $\begin{array}{c}\text { Articles on similar topics can be found in the following collections } \\
\text { Cranial nerves (421 articles) } \\
\text { Ear, nose and throat/otolaryngology (166 articles) } \\
\text { Neuromuscular disease (1048 articles) } \\
\text { Peripheral nerve disease (528 articles) } \\
\text { Drugs: CNS (not psychiatric) (1456 articles) } \\
\text { Ophthalmology (678 articles) }\end{array}$ \\
\hline
\end{tabular}

Notes

To request permissions go to:

http://group.bmj.com/group/rights-licensing/permissions

To order reprints go to:

http://journals.bmj.com/cgi/reprintform

To subscribe to BMJ go to:

http://group.bmj.com/subscribe/ 